\title{
Evaluating the Rationale for Affirmative Action in College Admissions: Direct and Indirect Relationships between Campus Diversity and Gains in Understanding Diverse Groups
}

\author{
Gary R. Pike George D. Kuh Robert M. Gonyea
}

Affirmative action in college admissions is based on the premise that a diverse student body contributes to interactions among students from different backgrounds, which are in turn positively related to desirable outcomes of college. This study evaluates the merits of this rationale for affirmative action by examining the direct and indirect relationships between student-body diversity and students' gains in understanding people of other raciallethnic backgrounds. Data from a nationally representative sample of 428 colleges and universities participating in the National Survey of Student Engagement (NSSE) indicated that student-body diversity was indirectly, but not directly, related to gains in understanding people from diverse backgrounds. Results supported the use of affirmative action in college admissions, indicating that student body diversity is directly related to greater interaction among diverse groups, but not the quality of interpersonal relations on campus. Diversity of the student body was indirectly related to gains in understanding diverse groups, acting through informal interactional diversity.

It is imperative that colleges and universities prepare students to function effectively in a diverse society (Association of American Colleges and Universities, 1995; Bikson \& Law, 1994; Bowen \& Bok, 1998; Knefelkamp,
1998). One commonly endorsed approach to addressing this critical need is to imbue learning environments with different forms of human diversity. In recent years, many institutions have employed affirmative action in admissions decisions to increase the diversity of their student bodies (Palmer, 2001; Rudenstine, 2001). This is especially important for more selective institutions that rely on admissions test scores that are highly correlated with family income; as a result many talented students from lower socioeconomic backgrounds are systematically excluded from admission because their test scores are below institutional averages.

The legal justification for affirmative action in admissions is Justice Powell's University of California Regents $v$. Bakke (1978) opinion, which held that it is permissible to use race/ethnicity as one of several factors in admission decisions if racial/ethnic diversity is demonstrated to improve the quality of the educational experience (Palmer, 2001; Rudenstine, 2001). In June 2003, the Supreme Court in Grutter v. Bollinger et al. upheld Justice Powell's opinion, noting that narrowly tailored affirmative action plans were acceptable if they produced educational benefits. At the same time, the court noted in Gratz v. Bollinger et al. (2003) that a formula-driven approach that

Gary R. Pike is Executive Director of Information Management and Institutional Research and Associate Professor of Higher Education and Student Affairs at Indiana University Purdue University Indianapolis. George D. Kuh is Chancellor's Professor and Director of the Center for Postsecondary Research and Robert M. Gonyea is Associate Director of the Center for Postsecondary Research, both at Indiana University Bloomington. 
automatically awarded points to all minority applicants could not be justified (Brittain, 2004; Jordan, 2004).

The preponderance of evidence generally indicates that student-body diversity is positively related to the amount of interaction among diverse groups of students, and these interactions contribute to, among other things, greater openness to and understanding of diverse people (Adams, 1995; Astin, 1993; Chang, 2000, 2002; Chang, Denson, Sáenz, \& Misa, 2005; Flowers \& Pascarella, 1999; Globetti, Globetti, Brown, \& Smith, 1993; Gurin, 1999; Henderson-King \& Kaleta, 2000; Hurtado, 1992; Hurtado, Dey, Gurin, \& Gurin, 2003; Hurtado, Milem, ClaytonPedersen, \& Allen, 1998, 1999; Milem, Chang, \& Antonio, 2005; Pascarella, Edison, Nora, Hagedorn, \& Terenzini, 1996; Pascarella \& Terenzini, 2005; Pike, 2002; Smith et al., 1997; Taylor, 1998; Whitt, Edison, Pascarella, Terenzini, \& Nora, 2001). These positive effects of student-body diversity are thought to be indirect and mediated by interactions with peers, what Gurin called informal interactional diversity. In addition, studentbody diversity is linked to enhanced intellectual development (Antonio, 2001; Chang et al.; Gurin; S. Hu \& Kuh, 2003; Pascarella, Palmer, Moye, \& Pierson, 2001; Pascarella \& Terenzini; Terenzini, Cabrera, Colbeck, Bjorklund, \& Parente, 2001; Umbach \& Kuh, 2006), gains in personal and social development (Antonio; Chang, 1999; S. Hu \& Kuh; Umbach \& Kuh), and positive perceptions of the campus environment (Chang, 1999; Gurin; Umbach $\&$ Kuh).

Not everyone accepts that student-body diversity is an educational benefit because it does not necessarily lead to or allow for a free exchange of ideas or other desirable outcomes of college (Clegg, 2005; Lerner \& Nagai, 2003; Wood \& Sherman, 2001). Some have sug- gested that diversity initiatives may harm rather than improve relations among different racial and ethnic groups (Bloom, 1987; D’Souza, 1991; Nieli, 2004). For example, Lerner and Nagai and Wood and Sherman pointed out that the findings of Astin (1993), Chang (1999), and Gurin (1999) rest on very weak correlations between student-body diversity and educational outcomes. They further noted the absence of a direct relationship between diversity and desired educational outcomes. Moreover, Lerner and Nagai argued that the weak zero-order correlations between student-body diversity and learning outcomes suggest that the indirect effects reported in earlier research may be statistical artifacts. Wood and Sherman emphasized that much of the existing diversity research incorrectly equates statistical significance with educational importance (i.e., effect size) and that these statistically significant relationships are largely a product of large sample sizes and do not necessarily represent an accurate estimate of the educational importance of the relationships. They also raised a non-trivial conceptual issue that Justice Powell's rationale for affirmative action in college admissions presumes that a diverse student body leads to interactions with peers who hold different views of the world. They, along with Clegg, contended that the content of these contacts among students from different racial and ethnic backgroundsassuming they occur with reasonable frequency to have an impact - do not necessarily represent diverse viewpoints on substantive issues. Therefore, to be justified on educational grounds, it must be demonstrated empirically that affirmative action in college admissions both contributes to interactions among people from different backgrounds and that these interactions be associated with more differentiated views on topics of educational substance. 


\section{Purpose and Scope}

This study was designed to determine whether affirmative action in college admissions is justified by examining the direct and indirect relationships between student-body diversity, the amount and quality of interactions among diverse groups of students, and students' gains in understanding diversity. Using data from a nationally representative sample of colleges and universities, we examine the statistical and educational significance of relationships among diverse people and understanding diverse groups. The analyses are done at the institution level in order to estimate the educational value of student interactions on campus and the benefits associated with these interactions. Arguably, campuses employ affirmative action policies to diversify the student body, thus increasing the prospects that diverse peers will interact and result in such desired outcomes as an enhanced appreciation for human diversity and an enlarged capacity to work productively with people from different backgrounds.
The results of this inquiry are important because, as Justice Scalia noted in his dissenting opinion in Grutter v. Bollinger et al. (2003), future court cases may focus on whether any educational benefits flow from racial diversity. Equally important, public opinion waxes and wanes about the value of diverse educational settings. Additional empirical evidence is needed to further document the veracity of claims made by those who support or oppose affirmative action in order to better inform the public about the impact of related policy options.

\section{RESEARCH METHODS Conceptual Model}

Figure 1 shows the conceptual model guiding the data analysis. In the model, institutional characteristics and campus diversity (i.e., diversity of the student body) are exogenous constructs, whereas the amount of interaction among diverse groups, the quality of those interactions, and gains in understanding diversity are endogenous constructs. Based on

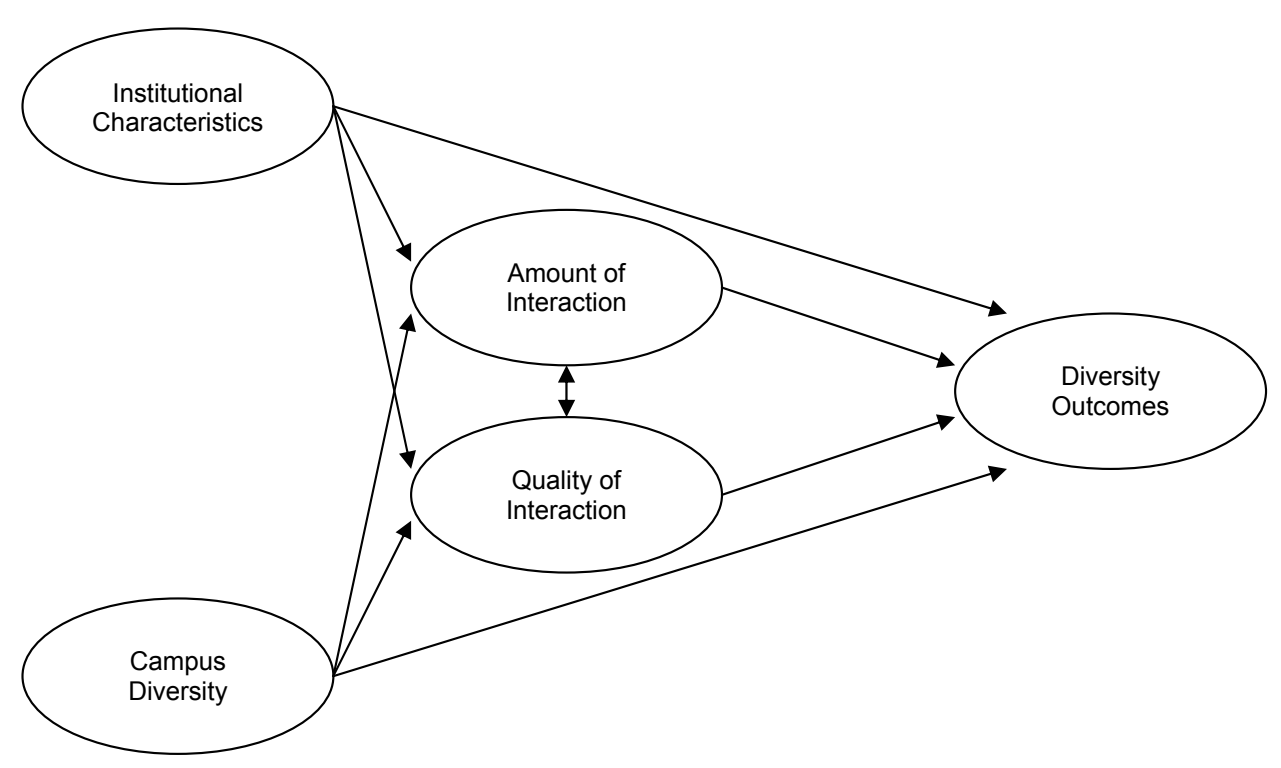

FIGURE 1. Conceptual model of the relationships among institutional characteristics, campus diversity, peer interaction, and diversity outcomes. 
the findings of previous research, gains in understanding diversity are presumed to be directly related to institutional characteristics, campus diversity, the amount of interaction among diverse groups, and the quality of interpersonal relations on campus (Chang et al., 2005; Hurtado et al., 1998, 1999, 2003; Milem et al., 2005). Institutional characteristics and campus diversity are also presumed to be directly related to the amount of interaction among diverse peers and the quality of interpersonal relations. Once again, research supports this assumption (see Chang, 2001; Pike \& Kuh, 2005, in press; Umbach \& Kuh, 2006). Institutional characteristics and campus diversity, mediated by the amount of interaction among diverse peers and quality of interpersonal relations, are indirectly related to gains in understanding diverse groups.

\section{Data Sources}

The data for this study came from the National Survey of Student Engagement's (NSSE) 2004 administration of The College Student Report, the Integrated Postsecondary Education Data System (IPEDS) data files, and Barron's ratings of institutional selectivity. The initial NSSE sample consisted of approximately 560,000 first-year and senior students attending 473 four-year colleges and universities. Students at 200 colleges and universities (42\%) had the option of responding via either a paper-andpencil questionnaire or the Web, and 175 schools (37\%) opted for Web-only administration. In 2004, NSSE introduced Web+ administration that included multiple electronic contacts and mailing a paper-and-pencil survey to selected non-respondents. A total of 98 institutions (21\%) selected this method of administration (Indiana University Center for Postsecondary Research, 2004). Complete data were available for 428 institutions, and these institutions were included in the present research.
The institutions in the study are very similar to the national profile in terms of geographic region and urban-rural locale. Public institutions and Master's universities are slightly overrepresented, whereas Baccalaureate-General colleges are somewhat underrepresented (NSSE, 2004).

The average institutional response rate for the NSSE 2004 survey was 40\%. Approximately $13 \%$ of the respondents completed the paper version of the survey, and $87 \%$ used the Web. Generally, administration mode does not affect the results, except that Web respondents tend to report greater use of electronic technology (Carini, Hayek, Kuh, Kennedy, \& Ouimet, 2003). The characteristics of NSSE respondents were very similar to those of students enrolled at NSSE 2004 institutions and students at all four-year colleges and universities (NSSE, 2004). Females were somewhat overrepresented among the respondents. However, the differences were small and should not affect the generalizability of the results.

\section{Measures}

Questions from The College Student Report were used to create the two measures of interactional diversity (i.e., amount of interaction and quality of interpersonal relationships), as well as the measure of gains in understanding diverse groups. Survey responses were also used to create two measures of institutional characteristics: (a) the percent of female students and (b) the percent of full-time students. The NSSE survey asks students to indicate the frequency with which they engage in activities that represent good educational practice and to report how much they have learned or gained in a variety of areas (Kuh et al., 2001). Self-report data are widely used in research on college effects, and the reliability and validity of these data have been studied extensively (see Baird, 1976; Berdie, 1971; Pace, 1985; Pike, 1995; Pohlmann \& Beggs, 
1974). Research shows that self-report measures are likely to be valid under five conditions:

1. the information requested is known to the respondents;

2. the questions are phrased clearly and unambiguously;

3. the questions refer to recent activities;

4. the respondents think the questions merit a serious and thoughtful response; and

5. answering the questions does not threaten, embarrass, or violate the privacy of the respondent or encourage the respondent to respond in socially desirable ways. (Kuh, 2001, p. 4)

The College Student Report meets these criteria and yields accurate, meaningful information about students' college experiences (Kuh, 2001; Kuh et al., 2001; Ouimet, Bunnage, Carini, Kuh, \& Kennedy, 2004).

The two measures of interactional diversity used in the study were based on three questions each from the NSSE survey. The first measure, the amount of interaction among diverse groups, represented Wood and Sherman's (2001) concept of viewpoint diversity and included questions about how often students had serious conversations with students of another racial or ethnic group; how often students had serious conversations with students with different religious beliefs, political opinions, or personal values; and the extent to which the institution encouraged contact among students from different groups. Response options for the first two questions were very often, often, sometimes, and never. Response options for the third question were very much, quite a bit, some, and very little.

The second measure, the nature of interpersonal relations, focused on students' relationships with other students, faculty members, and administrative personnel and offices. Response options were seven-point semantic differential scales. For relationships with students, the poles of the scale were friendly, supportive, sense of belonging and unfriendly, unsupportive, sense of alienation. For relationships with faculty members, the extremes were available, helpful, sympathetic and unavailable, unhelpful, unsympathetic. Helpful, considerate, flexible and unhelpful, inconsiderate, and rigid served as the poles for the question about relationships with administrative personnel and offices. Consistent with perceptual views of learning environments (Kuh, 2000; Strange \& Banning, 2001) these items taken together serve as a proxy for the quality of interpersonal relations on campus and constitute a campus climate measure of interpersonal support for learning.

The measure of understanding diverse people that was used in this research was based on a single question: To what extent has your experience at this institution contributed to your knowledge, skills, and personal development in understanding people of other racial and ethnic backgrounds? The response options for this question were very much, quite a bit, some, and very little.

Responses to each NSSE question were scaled from 0 to 100 using procedures developed by NSSE staff (Indiana University Center for Postsecondary Research, 2005). Scale scores were the means of the items comprising the scales. Thus, all scale scores ranged from 0 (low) to 100 (high).

Institutional characteristics obtained from IPEDS data were institutional control (coded $1=$ private, 0 = public), Carnegie classification (dummy coded as Doctoral/Research-Extensive, Doctoral/Research-Intensive, Master's, Baccalaureate Liberal Arts, and Baccalaureate General [not coded]), and urbanicity ( 1 = urban, $0=$ not urban). An institution was coded as urban if it was located in a city or urban fringe area. Three other institutional characteristics were included in the study. Selectivity was 
measured by Barron's selectivity ratings. The rating scale ranges from 1 to 7 with 1 representing open admissions, 6 representing highly selective admissions, and 7 representing a special category. Ratings from 1 to 6 were used in this study. The percent of female students was the percent of NSSE respondents who indicated they were female, and the percent of full-time students was the percent of NSSE respondents who indicated they were full-time students.

A modified version of Chang's (1999) diversity index was used as the measure of the diversity of an institution's student population. Although the index represents a very idealistic view of campus diversity, it provides significant advantages over traditional measures of campus diversity. Chang (1999) reasoned that more traditional measures of diversity, such as the percentage of minority students at an institution, are flawed because relatively homogeneous minority-serving institutions would be considered racially diverse. His index, presented below, measures the variance in the student population across four racial/ethnic groups: African American (Black), Asian American (Asian), Hispanic/Latino (Hispanic), and Caucasian (White). The value for $\mu$ in the equation is the average of the percentages for the four racial/ethnic groups. The index rewards heterogeneity in the student population. Institutions with similar percentages of students across all four groups (e.g., 25\%, $25 \%, 20 \%$, and 30\%) have higher diversity index scores than institutions with dissimilar percentages of students across all four groups (e.g., 5\%, 10\%, 5\%, and 80\%). The index used in this study was a modified version of the index used by Chang (1999). The modified index subtracted the deviation score from 1 , rather than calculating a reciprocal of the deviation score. The practical result of this modification was that all index scores ranged from 0 to 1 , with higher scale scores representing more heterogeneous student populations.

$1-\sqrt{\frac{(\% \text { Asian }-\mu)^{2}+(\% \text { Black }-\mu)^{2}+(\% \text { Hispanic }-\mu)^{2}+(\% \text { White }-\mu)^{2}}{4}}[1]$

\section{Data Analysis}

Initially, correlations among the diversity measures (i.e., campus diversity, amount of interaction among diverse peers, quality of interactions, and gains in understanding) were calculated and examined to determine if campus diversity was related to the other diversity measures. Because previous research found that relationships differed for first-year and senior students (Umbach \& Kuh, 2006), separate analyses were conducted for the two groups of students. Next, covariance matrices for all variables were calculated and analyzed using the Lisrel 8.72 computer program (Jöreskog \& Sörbom, 2005). Eight models were specified and tested for each group. The first was a saturated model in which all possible relationships among institutional characteristics and diversity measures were free to vary. The model served as a baseline for specifying and testing the second model.

In the second model, nonsignificant relationships between general institutional characteristics and the endogenous diversity measures were removed (i.e., fixed to zero). Goodness-of-fit tests were used to evaluate the appropriateness of eliminating relationships in the second model. The chi-square statistic provided an omnibus measure of model fit. Because chi-square results are influenced by sample size, a two-index test of model fit was also used (L. Hu \& Bentler, 1999). The indices used in this study were the standardized root mean square residual (SRMR) and the comparative fit index (CFI). Both indices are robust with respect to departures from multivariate normality and are insensitive to the effects of sample size (L. Hu \& Bentler, 1998, 1999). The values of $S R M R \leq 0.05$ and $\mathrm{CFI} \geq 0.96$ were used as criteria for selecting 
a suitable model (L. Hu \& Bentler, 1999). Because the educational importance of relationships was a focus of the present research, changes in explained variance (i.e., squared multiple correlations) were used to evaluate whether relationships should be removed from the model.

Once an appropriate second model was identified, five more models (Models 3-7) were specified and tested to evaluate the relationships among diversity measures. The third model removed the relationship between campus diversity and the frequency of interactions among diverse peers; the fourth model removed the relationship between campus diversity and the nature of interpersonal relations, and the fifth model eliminated the relationship between campus diversity and gains in understanding groups of diverse individuals. The relationship between the amount of interaction among diverse peers and gains in understanding was removed in the sixth model, and the relationship between the nature of interpersonal relations and gains was eliminated in the seventh model. Chi-square statistics, along with SRMR, CFI, and estimates of explained variance, were used to assess model fit.

Based on the results for Models 3-7, a final model was specified and tested for goodness of fit. Standardized direct, indirect, and total effects were calculated for the final model and used to describe the relationships among institutional characteristics, campus diversity, interactions among diverse peers, quality of interactions on campus, and gains in openness to diversity.

\section{RESULTS}

The correlations among diversity measures for first-year students indicate that campus diversity was significantly related to the frequency of interaction among diverse peers
(0.36) and gains in understanding diversity (0.30), but it was not related to the nature of interpersonal relations on campus (-0.09). Both the amount of interactions and nature of relations were significantly related to gains in understanding diversity for first-year students ( 0.65 and 0.22 , respectively). The pattern of relationships was the same for seniors. Campus diversity was significantly related to the amount of interaction among diverse peers (0.34) and gains in understanding (0.30), but it was not related to the quality of interactions $(-0.08)$. Both the amount of interaction and the quality of those interactions were significantly related to gains in understanding diverse groups (0.70 and 0.24, respectively). A complete set of descriptive statistics and correlations is available from the first author. Based on these findings, an analysis of the direct and indirect relationships between campus diversity and the other diversity measures was undertaken.

The goodness-of-fit results for first-year and senior students demonstrate that eliminating the nonsignificant relationships between institutional characteristics and the endogenous diversity measures (Model 2) did not significantly reduce goodness of model fit (Table 1). Likewise, removing the relationship between campus diversity and quality of interactions (Model 4) and removing the relationship between campus diversity and gains in understanding diversity (Model 5) did not substantially affect model fit. However, eliminating the relationship between quality of interactions and gains in understanding diversity (Model 7) did produce a statistically significant chi-square result, but the SRMR and CFI values were within acceptable ranges and the effect on estimates of explained variance were minimal. In contrast, eliminating the relationship between campus diversity and the amount of interaction among diverse peers (Model 3) and eliminating the relationship between the 
TABLE 1.

Goodness-of-Fit Results for First-Year and Senior Students

\begin{tabular}{cccccccc}
\hline & $d f$ & $\chi^{2}$ & SRMR & CFI & $R^{2}$ amt. & $R^{2}$ qual. & $R^{2}$ gains \\
\hline First-Year & & & & & & & \\
Model 1 & 0 & 0.00 & & & 0.38 & 0.43 & 0.58 \\
Model 2 & 11 & 17.40 & 0.01 & 1.00 & 0.38 & 0.42 & 0.56 \\
Model 3 & 12 & $81.04 *$ & 0.04 & 0.96 & 0.28 & 0.42 & 0.56 \\
Model 4 & 12 & 20.16 & 0.01 & 0.99 & 0.38 & 0.42 & 0.56 \\
Model 5 & 12 & 18.60 & 0.01 & 1.00 & 0.38 & 0.42 & 0.56 \\
Model 6 & 12 & $256.53 *$ & 0.05 & 0.85 & 0.38 & 0.42 & 0.23 \\
Model 7 & 12 & $29.79 *$ & 0.02 & 0.99 & 0.38 & 0.42 & 0.55 \\
Model 8 & 14 & $33.00 *$ & 0.02 & 0.99 & 0.38 & 0.42 & 0.55 \\
Senior & & & & & & & \\
Model 1 & 0 & 0.00 & & & 0.29 & 0.35 & 0.65 \\
Model 2 & 7 & 8.89 & 0.01 & 1.00 & 0.29 & 0.35 & 0.65 \\
Model 3 & 8 & $66.26 *$ & 0.04 & 0.96 & 0.19 & 0.35 & 0.65 \\
Model 4 & 8 & 9.97 & 0.01 & 1.00 & 0.29 & 0.35 & 0.65 \\
Model 5 & 8 & 9.70 & 0.01 & 1.00 & 0.29 & 0.35 & 0.65 \\
Model 6 & 8 & $325.04 *$ & 0.06 & 0.79 & 0.29 & 0.35 & 0.25 \\
Model 7 & 8 & 16.29 & 0.01 & 0.99 & 0.29 & 0.35 & 0.64 \\
Model 8 & 10 & 17.78 & 0.01 & 0.99 & 0.29 & 0.35 & 0.64 \\
\hline
\end{tabular}

Note. SRMR = Standardized Root mean Square Residual; CFI = Comparative Fit Index; $R^{2}$ Amt. $=R^{2}$ Amount of Interaction; $R^{2}$ Qual. $=R^{2}$ Quality of Interaction; $R^{2}$ Gains $=R^{2}$ Gains in Understanding Diverse Groups.

$* p<0.05$.

amount of interaction among diverse peers and gains in understanding diversity (Model 6) substantially reduced model fit. The final model, which included statistically significant relationships between institutional characteristics and diversity measures, campus diversity and the amount of interaction among diverse peers, and amount of interaction among diverse peers and gains in understanding diversity (Model 8), provided an acceptable representation of the observed data and accounted for a substantial proportion of the variance in the three endogenous diversity measures.

Essentially the same results were found for seniors. The final model, which included the statistically significant relationships between institutional characteristics and diversity measures, the relationship between campus diversity and the amount of interaction among diverse peers, and the relationship between amount of interaction and gains in understanding diversity (Model 8), provided an acceptable representation of the observed data. 
Standardized coefficients representing the relationships among institutional characteristics, campus diversity, the amount and quality of interactions among diverse peers, and diversity gains for first-year students are presented in Table 2. Seven institutional characteristics were positively related to the amount of interaction among diverse peers on a campus: being a Private institution, being a Doctoral/Research-Extensive university, being a Baccalaureate Liberal Arts institution, institutional selectivity, being located in an urban area, the percent of female students, and the percent of full-time students. Combined, these institutional characteristics accounted for $28 \%$ of the variance in the amount of interaction among diverse peers across institutions. Campus diversity also was positively related to interactional diversity and accounted for an additional $10 \%$ of the variance in interaction among diverse peers.

Six measures of institutional characteristics were related to first-year students' reports of the quality of interpersonal relationships on campus. Being a Private institution and institutional selectivity were positively related to the quality of interpersonal relations, whereas being a Doctoral/Research-Extensive, Doctoral/Research-Intensive, or Master's university, as opposed to being a BaccalaureateGeneral college, was negatively related to the reported quality of interpersonal relations at an institution. Being in an urban locale also was negatively related to the reported quality of interpersonal relations on campus. These institutional characteristics accounted for $42 \%$ of the variance in the quality of interactions across institutions. As previously noted, campus diversity was not related to the quality of interpersonal relationships in this model.

The gains in understanding diversity for first-year students were directly and positively related to the institution being located in an urban area and the percent of female students responding to the survey. Both of these institutional characteristics also were indirectly related to diversity gains. Institutional selectivity was directly and negatively related to gains in understanding diversity. Although selectivity had a positive indirect relationship with gains due to the positive relationship between selectivity and the amount of interaction among diverse peers, the overall (i.e., total) relationship between selectivity and gains for first-year students was negative. Being a Private institution, a Doctoral/Research-Extensive university, and a Baccalaureate Liberal Arts institution were also positively and indirectly related to levels of first-year students' gains in understanding diversity across institutions. Institutional characteristics accounted for $23 \%$ of the variance in average gain scores across institutions.

Although campus diversity was not directly related to first-year students' reported gains in understanding diversity, there was a substantial positive indirect relationship between campus diversity and gains owing to the positive relationship between campus diversity and interactions among diverse peers, coupled with the substantial positive relationship between the amount of interaction among diverse peers and diversity gains. Interactional diversity accounted for $32 \%$ of the variance in first-year students' gains in understanding diversity across institutions.

Table 3 presents the direct, indirect, and total relationships in the final model for seniors. Levels of interaction among diverse peers were positively related to seven institutional characteristics: being a Private institution, being a Doctoral/ResearchExtensive university, being a Master's university, being a Baccalaureate Liberal Arts institution, being located in an urban area, the percent of female students, and the percent of full-time students responding to the NSSE survey. Combined, these institutional charac- 
TABLE 2.

Standardized Parameters for the Final Model of First-Year Students

\begin{tabular}{|c|c|c|c|c|}
\hline & & $\begin{array}{l}\text { Interactional } \\
\text { Diversity }\end{array}$ & $\begin{array}{c}\text { Quality of } \\
\text { Interactions }\end{array}$ & $\begin{array}{c}\text { Gains in } \\
\text { Understanding }\end{array}$ \\
\hline \multirow[t]{3}{*}{ Private Institution } & Direct & $0.16 *$ & $0.45^{*}$ & 0.00 \\
\hline & Indirect & & & $0.12 *$ \\
\hline & Total & $0.16 *$ & $0.45^{*}$ & $0.12 *$ \\
\hline \multirow[t]{3}{*}{ Doctoral/Research-Extensive } & Direct & $0.09 *$ & $-0.22 *$ & 0.00 \\
\hline & Indirect & & & $0.06 *$ \\
\hline & Total & $0.09 *$ & $-0.22 *$ & $0.06^{*}$ \\
\hline \multirow[t]{3}{*}{ Doctoral/Research-Intensive } & Direct & 0.00 & $-0.24 *$ & 0.00 \\
\hline & Indirect & & & 0.00 \\
\hline & Total & 0.00 & $-0.24 *$ & 0.00 \\
\hline \multirow[t]{3}{*}{ Master's | \& || } & Direct & 0.00 & $-0.11 *$ & 0.00 \\
\hline & Indirect & & & 0.00 \\
\hline & Total & 0.00 & -0.11 & 0.00 \\
\hline \multirow[t]{3}{*}{ Baccalaureate-Liberal Arts } & Direct & $0.27 *$ & 0.00 & 0.00 \\
\hline & Indirect & & & $0.19 *$ \\
\hline & Total & $0.27 *$ & 0.00 & $0.19 *$ \\
\hline \multirow[t]{3}{*}{ Selectivity } & Direct & $0.13^{*}$ & $0.12 *$ & $-0.29 *$ \\
\hline & Indirect & & & $0.09 *$ \\
\hline & Total & $0.13 *$ & $0.12 *$ & $-0.20 *$ \\
\hline \multirow[t]{3}{*}{ Urban Locale } & Direct & $0.14^{*}$ & $-0.19 *$ & $0.06 *$ \\
\hline & Indirect & & & $0.10 *$ \\
\hline & Total & $0.14 *$ & $-0.19 *$ & $0.16 *$ \\
\hline \multirow[t]{3}{*}{ Percent of Female Students } & Direct & $0.10 *$ & 0.00 & $0.16 *$ \\
\hline & Indirect & & & $0.07^{*}$ \\
\hline & Total & $0.10 *$ & 0.00 & $0.23^{*}$ \\
\hline \multirow[t]{3}{*}{ Percent of Full-Time Students } & Direct & $0.12 *$ & 0.00 & 0.00 \\
\hline & Indirect & & & $0.09 *$ \\
\hline & Total & $0.12 *$ & 0.00 & $0.09 *$ \\
\hline \multirow[t]{3}{*}{ Diversity Index } & Direct & $0.34 *$ & 0.00 & 0.00 \\
\hline & Indirect & & & $0.25^{*}$ \\
\hline & Total & $0.34 *$ & 0.00 & $0.25 *$ \\
\hline \multirow[t]{3}{*}{ Interactional Diversity } & Direct & & & $0.72 *$ \\
\hline & Indirect & & & \\
\hline & Total & & & $0.72 *$ \\
\hline \multirow[t]{3}{*}{ Quality of Interactions } & Direct & & & 0.00 \\
\hline & Indirect & & & \\
\hline & Total & & & 0.00 \\
\hline Squared Multiple Correlation $\left(R^{2}\right)$ & & 0.38 & 0.42 & 0.55 \\
\hline
\end{tabular}

$* p<0.05$. 
teristics accounted for $19 \%$ of the variance in the amount of interaction among diverse peers across institutions. Campus diversity also was positively related to interactional diversity and accounted for $10 \%$ of the variance across institutions.

The quality of interpersonal relations reported by seniors was positively related to whether an institution was a private college or university. Five other institutional characteristics were negatively related to the quality of an institution's interpersonal environment for seniors: being a Doctoral/Research-Extensive university, being a Doctoral/Research-Intensive university, being a Master's university, being located in an urban area, and the percent of full-time students. These institutional characteristics accounted for $35 \%$ of the variance in seniors' reports of the quality of interpersonal relations across institutions.

Being a Doctoral/Research-Extensive, Doctoral/Research-Intensive, Master's, or Baccalaureate Liberal Arts institution was directly and negatively related to levels of understanding diversity. Owing to the positive direct relationships between interactional diversity and being a Doctoral/ResearchExtensive or Baccalaureate Liberal Arts institution, the negative direct relationships between diversity gains and these two institutional types were offset by indirect relationships. The negative direct relationship between gains in understanding diversity and being a Master's university was partly offset by the indirect relationship, acting through the amount of interaction among diverse peers.

Both institutional selectivity and the percent of full-time students were directly and negatively related to gains in understanding diversity. The negative direct relationship for the percent of full-time students was offset by a positive indirect relationship for full-time students. Neither being a private institution nor being an urban institution was directly related to diversity gains, although both were indirectly and positively related to gains in understanding diverse groups. The direct, indirect, and total relationships between gains in understanding diversity and the percent of female students responding to the survey were positive and statistically significant. Taken together, institutional characteristics accounted for $25 \%$ of the variance in diversity gains across institutions.

Although campus diversity was not directly related to gains in understanding diversity, the indirect relationship was positive and statistically significant. The mediating variable in the indirect relationship, the amount of interaction among diverse peers, had a substantial and positive direct relationship with gains in understanding diversity. For seniors, the relationship between interactional diversity and understanding accounted for 39\% of the variance in diversity gains across institutions.

\section{Limitations}

The results from the 2004 NSSE survey are generally consistent with the results from other NSSE administrations. However, because only one year of data was analyzed in this study the results might differ in unknown ways if institutions participating in other years were included. In addition, The College Student Report is a relatively short survey and does not measure many relevant aspects of students' diversity experiences or potential outcomes of diversity initiatives. In addition, using a single item to represent understanding diverse groups provides a narrow view of diversity outcomes. If additional questions were included in the survey, different results might have emerged.

Information about diversity initiatives at participating institutions, and whether the students responding to the survey participated in those initiatives, was not available to the researchers. As valuable as this information would be in explaining additional variance in 
TABLE 3.

Standardized Parameters for the Final Model of Seniors

\begin{tabular}{|c|c|c|c|c|}
\hline & & $\begin{array}{l}\text { Interactional } \\
\text { Diversity }\end{array}$ & $\begin{array}{l}\text { Quality of } \\
\text { Interactions }\end{array}$ & $\begin{array}{c}\text { Gains in } \\
\text { Understanding }\end{array}$ \\
\hline \multirow[t]{3}{*}{ Private Institution } & Direct & $0.12 *$ & $0.36 *$ & 0.00 \\
\hline & Indirect & & & $0.09 *$ \\
\hline & Total & $0.12 *$ & $0.36 *$ & $0.09 *$ \\
\hline \multirow[t]{3}{*}{ Doctoral/Research-Extensive } & Direct & $0.14 *$ & $-0.27^{*}$ & $-0.12^{*}$ \\
\hline & Indirect & & & $0.11 *$ \\
\hline & Total & $0.14 *$ & $-0.27 *$ & -0.01 \\
\hline \multirow[t]{3}{*}{ Doctoral/Research-Intensive } & Direct & 0.00 & $-0.25 *$ & $-0.13^{*}$ \\
\hline & Indirect & & & 0.00 \\
\hline & Total & 0.00 & $-0.25^{*}$ & $-0.13^{*}$ \\
\hline \multirow[t]{3}{*}{ Master's | \& || } & Direct & 0.10 & $-0.12^{*}$ & $-0.18^{*}$ \\
\hline & Indirect & & & $0.08 *$ \\
\hline & Total & $0.10 *$ & $-0.12^{*}$ & $-0.10^{*}$ \\
\hline \multirow[t]{3}{*}{ Baccalaureate-Liberal Arts } & Direct & $0.33 *$ & 0.00 & $-0.15^{*}$ \\
\hline & Indirect & & & $0.25^{*}$ \\
\hline & Total & $0.33 *$ & 0.00 & $0.10 *$ \\
\hline \multirow[t]{3}{*}{ Selectivity } & Direct & 0.00 & 0.00 & $-0.17^{*}$ \\
\hline & Indirect & & & 0.00 \\
\hline & Total & 0.00 & 0.00 & $-0.17^{*}$ \\
\hline \multirow[t]{3}{*}{ Urban Locale } & Direct & $0.11 *$ & $-0.30 *$ & 0.00 \\
\hline & Indirect & & & $0.09 *$ \\
\hline & Total & $0.11 *$ & $-0.30 *$ & $0.09 *$ \\
\hline \multirow[t]{3}{*}{ Percent of Female Students } & Direct & $0.12 *$ & 0.00 & $0.15^{*}$ \\
\hline & Indirect & & & $0.09 *$ \\
\hline & Total & $0.12 *$ & 0.00 & $0.24 *$ \\
\hline \multirow[t]{3}{*}{ Percent of Full-Time Students } & Direct & $0.11 *$ & $-0.15^{*}$ & $-0.12^{*}$ \\
\hline & Indirect & & & $0.09 *$ \\
\hline & Total & $0.11 *$ & $-0.15^{*}$ & -0.03 \\
\hline \multirow[t]{3}{*}{ Diversity Index } & Direct & $0.35^{*}$ & 0.00 & 0.00 \\
\hline & Indirect & & & $0.26 *$ \\
\hline & Total & $0.35^{*}$ & 0.00 & $0.26 *$ \\
\hline \multirow[t]{3}{*}{ Interactional Diversity } & Direct & & & $0.76^{*}$ \\
\hline & Indirect & & & \\
\hline & Total & & & $0.76^{*}$ \\
\hline \multirow[t]{3}{*}{ Quality of Interactions } & Direct & & & 0.00 \\
\hline & Indirect & & & \\
\hline & Total & & & 0.00 \\
\hline Squared Multiple Correlation $\left(R^{2}\right)$ & & 0.29 & 0.35 & 0.64 \\
\hline
\end{tabular}

$*_{p}<0.05$. 
diversity outcomes, doing so requires that individual institutions link additional information about students' college experiences, such as transcripts and participation in diversity initiatives, which would be an enormously time-consuming task. Although it was important that institutions be the unit of analysis, given the purposes of the study, aggregation bias is a possible consequence of the use of institution-level data (Burstein, 1980). At a minimum, the estimates of explained variance are greater than in many studies because student-level variance is not included in the models. Finally, the data used in this study were cross-sectional, not longitudinal. As a consequence, it is not possible to make causal claims about the effects of diversity initiatives on patterns of interactions, college environments, and diversity outcomes. As with incorporating additional information about students' experiences beyond that collected by NSSE, longitudinal analyses demand data not presently available to the researchers or most institutions that participate in NSSE.

\section{DISCUSSION}

Despite these limitations, the results of the present research have important implications for theory and practice. First and foremost, the findings of this study suggest that greater diversity in the student population is associated with higher levels of interaction among peers from different backgrounds and who held different views. Higher levels of interactional diversity, in turn, are associated with greater gains in understanding people from different races and cultures. These relationships corroborate the legal position argued by Justice Powell in University of California Regents $v$. Bakke (1978) that a diverse student body enhances the quality of the educational experience on college campus.
The present research also speaks to certain issues raised by critics of affirmative action admission policies. Unlike many earlier studies that relied on convenience samples of freshmen, this study is based on nationally representative samples of students and institutions. In addition, the substantial amounts of variance explained ensure that the results are educationally as well as statistically significant. Finally, the results of this research also demonstrate that the racial and ethnic diversity of a student body is associated with exposure to diverse viewpoints as a result of informal interactions with peers.

At the same time, the results refute the claim that the use of affirmative action in college admissions is associated with negative perceptions of peers and the campus environment. Out findings indicate that the quality of interpersonal relations on campus was unrelated to diversity experiences, suggesting that admitting students of color neither insures an affirming campus environment nor does it lead to hostility, stereotyping, and debilitating inter-group relations.

It is troubling that the institutions that educate the majority of American college students-Public, Doctoral/Research, and Master's universities - had the least positive and affirming campus environments, at least in contrast to those of Baccalaureate-General colleges. Other studies have found that the quality of interpersonal relations on college campuses is related to a variety of positive educational outcomes, including educational success and attainment (Pascarella \& Terenzini, 2005). Clearly much work remains to be done to improve the quality of educational experiences on many college campuses.

One striking finding of the present research is that the pattern of relationships among campus diversity, frequency of informal interactions between students from different racial and ethnic backgrounds (interactional 
diversity), the quality of the interpersonal environment, and gains in understanding others were virtually identical for first-year and senior students. This finding differs from the results reported by Umbach and Kuh (2006). In part, the different results may be a function of using different measures and analytical approaches. For example, although Umbach and Kuh found campus diversity to be negatively related to satisfaction and perceived interpersonal support, this relationship disappeared when other factors were taken into account, such as offering courses that emphasize exposure to diverse perspectives and emphasizing the importance of interacting with peers from different backgrounds, variables that were not included in the present study.

The patterns of relationships between institutional characteristics and diversity measures for first-year and senior students differed in some noteworthy ways. In general, institutional characteristics were more strongly related to the amount of interaction among diverse peers and the quality of interactions across campus for first-year students than for seniors. Institutional characteristics accounted for $28 \%$ of the variance in interactions among diverse peers for first-year students, but only $19 \%$ of the variance for seniors. Similarly, institutional characteristics accounted for approximately $42 \%$ of the variance in the quality of interactions for first-year students and $35 \%$ of the variance for seniors. Perhaps this is because institutions tend to front load diversity programs, featuring such activities in orientation and throughout the first year in residence halls and specially designed student success courses. It is also possible that many first-year students come from relatively homogeneous environments, and college may be their first real opportunity to experience diversity. By the senior year, students have self-segregated at all types of institutions and live (often off campus) with students whose attitudes, values, and other characteristics are more like their own. Thus, many of the factors that make interactions with diverse peers inescapable early in the college years are no longer operating.

Another noteworthy finding is that institutional selectivity was related to the amount and quality of interactions for firstyear students, but not for seniors. At least in terms of diversity experiences, it appears that institutional selectivity is more important early in students' educational careers, rather than later. Perhaps this is because as with other aspects of the student experience, what students do as contrasted with who they are (or what they bring with them to campus) becomes more important to the nature and quality of their experiences over time. Selective colleges tend to be residential, thus putting more students into closer contact with peers as noted above.

Although institutional characteristics accounted for approximately the same proportions of variance in diversity gains for first-year and senior students (23\% and 25\%, respectively), measures of institutional mission (i.e., Carnegie classifications) were directly related to seniorss :' gains in understanding diversity, but not to the gains of first-year students. It would appear that the effects of general institutional characteristics, such as institutional mission, are modest and cumulative, requiring several years to manifest themselves as factors influencing students' learning outcomes.

Institutions become more diverse in two ways. The most common is when demographics in the surrounding area change. The second is by intentionally recruiting and supporting students, faculty, and staff from historically underrepresented populations to address diversity goals. In their study of 20 high performing colleges and universities, Kuh et al. 
(2005) found proactively recruiting students from diverse backgrounds was more effective than relying on applicant pools to naturally become more diverse. These institutions also made intentional efforts to insure that diverse perspectives were emphasized in the curriculum. That is, consistent with other research (e.g., Hurtado et al., 2003), the percentage of students from historically underserved populations present in the student body is less important in helping students understand dimensions of human diversity than is exposing students to different ways of thinking. These include assignments that feature socioeconomic class, internationalism, and global consciousness and expand students' worldviews and how they interpret and generate alternative solutions to problems. Ultimately, what really matters is that students encounter in their studies and through their interactions with diverse peers, faculty, and staff members perspectives that represent a range of human experiences that impel them to think and respond in novel, more complex ways.

\section{CONCLUSION}

Organizations such as the Association of American Colleges and Universities (Smith et al., 1997) and the Harvard Civil Rights Project (Orfield, 2001) have consistently argued that affirmative action in college admissions is needed to provide the conditions under which majority (i.e., White) students can interact with and learn about people who are different from themselves. These organi- zations have also argued that these interactions will result in a more affirming campus environment and help students learn to function effectively in a diverse society. This line of reasoning formed the basis for Justice Powell's opinion in University of California Regents v. Bakke (1978) and Justice O'Connor's majority opinion in Grutter v. Bollinger et al. (2003).

The results of this study support the claim that a diverse student population is associated with interactions among diverse peers and that this interaction is related to increased understanding of different racial and ethnic groups. At the same time, the diversity of the student body, as represented by the number of students from different racial and ethnic backgrounds, had no effect on how students perceived the campus environment. That is, interactions among diverse peers do not seem to make any difference as to whether students view the campus as supportive and affirming or alienating and hostile. This suggests that the quality of interpersonal relations as experienced by college students appears to be more a function of other institutional characteristics and the programs and practices colleges and universities provide to enhance student engagement and success for all their students.

Correspondence concerning this article should be addressed to Gary R. Pike, Executive Director, Information Management and Institutional Research, Indiana University Purdue University Indianapolis, $355 \mathrm{~N}$. Lansing Street, AO139G, Indianapolis, IN 462022896; pikeg@iupui.edu 


\section{REFERENCES}

Adams, S. E. (1995). The relationship between social contact and comfort with social interaction among student ethnic groups. NASPA Journal, 32, 251-261.

Antonio, A. L. (2001). The role of interracial interaction in the development of leadership skills and cultural knowledge and understanding. Research in Higher Education, 42, 593-617.

Association of American Colleges and Universities. (1995). American pluralism and the college curriculum: Higher education in a diverse democracy. Washington, DC: Author.

Astin, A. W. (1993). What matters in college? Four critical years revisited. San Francisco: Jossey-Bass.

Baird, L. L. (1976). Using self-reports to predict student performance. New York: The College Board.

Berdie, R. (1971). Self-claimed and tested knowledge. Educational and Psychological Measurement, 31, 629-636.

Bikson, T. K., \& Law, S. A. (1994). Global preparedness and human resources. Santa Monica, CA: RAND Institute on Education and Training.

Bloom, A. (1987). The closing of the American mind. New York: Simon and Schuster.

Bowen, W. G., \& Bok, D. (1998). The shape of the river: Longterm consequences of considering race in college and university admissions. Princeton, NJ: Princeton University Press.

Brittain, J. C. (2004). Affirmative action survives the test: Racial and ethnic diversity a benefit to higher education. The Houston Lawyer, 41(4), 18-23. Retrieved October 20, 2005, from http://www.thehoustonlawyer.com/aa_jan04/aa_ feature/page18/page18.htm

Burstein, L. (1980). The analysis of multilevel data in educational research and evaluation. In D. C. Berliner (Ed.), Review of research in education (Vol. 8, pp. 158-233). Washington, DC: American Educational Research Association.

Carini, R. M., Hayek, J. H., Kuh, G. D., Kennedy, J. M., \& Ouimet, J. A. (2003). College student responses to web and paper surveys: Does mode matter? Research in Higher Education, 44, 1-19.

Chang, M. J. (1999). Does racial diversity matter? The educational impact of a racially diverse undergraduate population. Journal of College Student Development, 40, 377-395.

Chang, M. J. (2000). Improving campus racial dynamics: A balancing act among competing interests. Review of Higher Education, 23, 153-175.

Chang, M. J. (2001). The positive educational effects of racial diversity on campus. In G. Orfield (Ed.), Diversity challenged: Evidence on the impact of affirmative action (pp. 175-186). Cambridge, MA: Harvard Civil Rights Project.

Chang, M. J. (2002). Preservation or transformation: Where's the real educational discourse on diversity? Review of Higher Education, 25, 125-140.

Chang, M. J., Denson, N., Sáenz, V., \& Misa, K. (2005, February). The educational benefits of sustaining cross-racial interaction among undergraduates. Retrieved October 27, 2005, from the University of California, Berkeley Center for Studies in Higher Education Web site: http://cshe.berkeley. edu/publications/publications. php?id=61

Clegg, R. (2005). Attacking "diversity": A review of Peter Wood's Diversity: The Invention of a Concept. Journal of College and
University Law, 31, 417-436. Retrieved October 27, 2005, from the Center for Equal Opportunity Web site: http:// www.ceousa.org/pdfs/roger-clegg_attacking_diversity.pdf

D’Souza, D. (1991). Illiberal education. New York: Free Press.

Flowers, L., \& Pascarella, E. T. (1999). Does college racial composition influence the openness to diversity of African American students? Journal of College Student Development, 40, 405-417.

Globetti, E. C., Globetti, G., Brown, C. L., \& Smith, R. E. (1993). Social interaction and multiculturalism. NASPA Journal, 30, 209-218.

Gratz v. Bollinger et al. 539 US 244 (2003).

Grutter v. Bollinger et al. 539 US 306 (2003).

Gurin, P. Y. (1999). Expert report of Patricia Gurin, Gratz, et al. v. Bollinger, et al., No. 97-75321, Grutter, et al. v. Bollinger, et al. Retrieved from the University of Michigan Web site May 3, 2004, from: http://www.umich.edu/ - urel/admissions/ legal/expert/summ.html

Henderson-King, D., \& Kaleta, A. (2000). Learning about social diversity: The undergraduate experience and intergroup tolerance. Journal of Higher Education, 71, 142-164.

$\mathrm{Hu}, \mathrm{L} .$, \& Bentler, P. M. (1998). Fit indices in covariance structure modeling: Sensitivity to underparameterized model misspecification. Psychological Methods, 3, 424-453.

Hu, L., \& Bentler, P. M. (1999). Cutoff criteria for fit indexes in covariance structure analysis: Conventional criteria versus new alternatives. Structural Equation Modeling, 6, 1-55.

Hu, S., \& Kuh, G. D. (2003). Diversity experiences and college student learning and personal development. Journal of College Student Development, 44, 320-334.

Hurtado, S. (1992). The campus racial climate: Contexts for conflict. Journal of Higher Education, 63, 539-569.

Hurtado, S., Dey, E. L., Gurin, P.Y., \& Gurin, G. (2003). College environments, diversity, and student learning. In J. C. Smart (Ed.), Higher education: Handbook of theory and research (Vol. XVIII, pp. 145-189). Dordrecht, Netherlands: Kluwer.

Hurtado, S., Milem, J. F., Clayton-Pedersen, A. R., \& Allen, W. (1998). Enhancing campus climates for racial/ethnic diversity: Educational policy and practice. Review of Higher Education, 21, 279-302.

Hurtado, S., Milem, J. F., Clayton-Pedersen, A. R., \& Allen, W. (1999). Enacting diverse learning environments: Improving the climate for raciallethnic diversity in higher education (ASHE-ERIC Higher Education Report Vol. 26, No. 8). Washington, DC: The George Washington University.

Indiana University Center for Postsecondary Research. (2004). NSSE 2004 overview. Bloomington, IN: Author.

Indiana University Center for Postsecondary Research. (2005). Benchmark construction syntax. Downloaded from the National Survey of Student Engagement web site: http:// www.iub.edu/ $\sim$ nsse/html/benchmark.htm

Jordan, G. W., III. (2004). Race-conscious university admissions challenges in attaining student body diversity in the Grutter/ Gratz era. The Houston Lawyer, 41(4), 10-17. Retrieved October 20, 2005, from http://www.thehoustonlawyer. com/aa_jan04/aa_feature/page10/page10.htm 
Jöreskog, K. G., \& Sörbom, D. (2005). Lisrel 8.72. Chicago, IL: Scientific Software International.

Knefelkamp, L. (1998). Diversity and education in a democratic society. Presentation at the American Commitments meeting of the Association of American Colleges and Universities, April, Ann Arbor, MI.

Kuh, G. D. (2000). Understanding campus environments. In M.J. Barr and M. Desler (Eds.), Handbook on student affairs administration (pp. 50-72) (2nd ed.). San Francisco: Jossey-Bass.

Kuh, G. D. (2001). The National Survey of Student Engagement: Conceptual framework and overview of psychometric properties. Bloomington, IN: Indiana University Center for Postsecondary Research.

Kuh, G. D., Hayek, J. C., Carini, R. M., Ouimet, J. A., Gonyea, R. M., \& Kennedy, J. (2001). NSSE technical and norms report. Bloomington, IN: Indiana University Center for Postsecondary Research and Planning.

Kuh, G. D., Kinzie, J., Schuh, J. H., Whitt, E. J., \& Associates (2005). Student success in college: Creating conditions that matter. San Francisco: Jossey-Bass.

Lerner, R., \& Nagai, A. K. (2003). A critique of the expert report of Patricia Gurin in Gratz v. Bollinger. Retrieved October 27, 2005 from the Center for Equal Opportunity web site: http://www.ceousa.org.pdfs/Gurin1.pdf.

Milem, J. F., Chang, M. J., \& Antonio, A. L. (2005). Making diversity work on campus: A research-based perspective. Retrieved October 27, 2005 from the Association of American Colleges and Universities web site: http//:www. aacu.org/inclusive_excellence/pdfs/Milem_Final.pdf.

National Survey of Student Engagement (2004). Student engagement: Pathways to collegiate success. Bloomington, IN: Indiana University Center for Postsecondary Research.

Nieli, R. K. (2004, October 4). The changing shape of the river: Affirmative action and recent social science research. Retrieved October 27, 2005 from the National Association of Scholars web site: http://www.nas.org/reports/river-change/affirmact_soc-sci.pdf.

Orfield, G. (Ed.). (2001). Diversity challenged: Evidence on the impact of affirmative action. Cambridge, MA: Harvard Civil Rights Project.

Ouimet, J. A., Bunnage, J. C., Carini, R. M., Kuh, G. D., \& Kennedy, J. (2004). Using focus groups, expert advice, and cognitive interviews to establish the validity of a college student survey. Research in Higher Education, 45, 233-250.

Pace, C. R. (1985). The credibility of student self-reports. Los Angeles: Center for the Study of Evaluation, University of California Los Angeles.

Palmer, S. R. (2001). A policy framework for reconceptualizing the legal debate concerning affirmative action in higher education. In G. Orfield (Ed.), Diversity challenged: Evidence on the impact of affirmative action (pp. 49-80). Cambridge, MA: Harvard Civil Rights Project.

Pascarella, E. T., Edison, M., Nora, A., Hagedorn, L. S., \& Terenzini, P. T. (1996). Influences on students' openness to diversity and challenge in the first year of college. Journal of Higher Education, 67, 174-195.
Pascarella, E. T., Palmer, B., Moye, M., \& Pierson, C. T. (2001). Do diversity experiences influence the development of critical thinking? Journal of College Student Development, 42, 257-271.

Pascarella, E. T., \& Terenzini, P. T. (2005). How college affects students: A third decade of research (Vol. 2). San Francisco: Jossey-Bass.

Pike, G. R. (1995). The relationship between self reports of college experiences and achievement test scores. Research in Higher Education, 36, 1-21.

Pike, G. R. (2002). The differential effects of on- and offcampus living arrangements on students' openness to diversity. NASPA Journal, 39, 283-299.

Pike, G. R., \& Kuh, G. D. (2005). A typology of student engagement for American colleges and universities. Research in Higher Education, 46, 185-210.

Pike, G. R., \& Kuh, G. D. (in press). Another look at the relationships among structural diversity, informal peer interactions and perceptions of the campus environment. Review of Higher Education.

Pohlmann, J., \& Beggs, D. (1974). A study of the validity of self-reported measures of academic growth. Journal of Educational Measurement, 11, 115-119.

Rudenstine, N. L. (2001). Student diversity and higher learning. In G. Orfield (Ed.), Diversity challenged: Evidence of the impact of affirmative action (pp. 31-48). Cambridge, MA: Harvard Civil Rights Project.

Smith, D. G., Gerbick, G. L., Figueroa, M. A., Watkins, G. H., Levitan, T., Moore, L. C., et al. (1997). Diversity works: The emerging picture of how students benefit. Washington, DC: American Association of Colleges and Universities.

Strange, C. C. \& Banning, J. H. (2001). Educating by design: Creating campus environments that work. San Francisco: Jossey-Bass.

Taylor, S. H. (1998). The impact of college on the development of tolerance. NASPA Journal, 35, 281-295.

Terenzini, P. T., Cabrera, A. F., Colbeck, C. L., Bjorklund, S. A., \& Parente, J. M. (2001). Racial and ethnic diversity in the classroom: Does it promote student learning? Journal of Higher Education, 72, 509-531.

Umbach, P. D., \& Kuh, G. D. (2006). Student experiences with diversity at liberal arts colleges: Another claim for distinctiveness. Journal of Higher Education, 77, 169-192

University of California Regents v. Bakke 438 U.S. 265 (1978).

Whitt, E. J., Edison, M. I., Pascarella, E. T., Terenzini, P. T., \& Nora, A. (2001). Influences on students' openness to diversity and challenge in the second and third years of college. Journal of Higher Education, 72, 172-204.

Wood, T. E., \& Sherman, M. J. (2001, May). Race and higher education: Why Justice Powell's diversity rationale for racial preferences in higher education must be rejected. Retrieved October 27, 2005 from the National Association of Scholars web site: http://www.nas.org/rhe.pdf 